
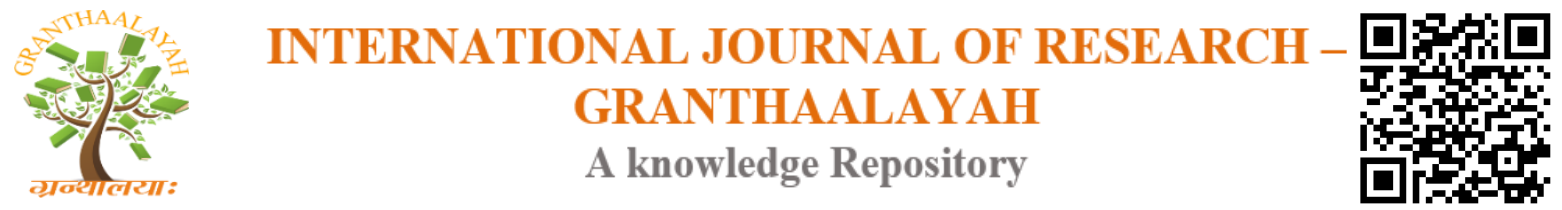

Science

\title{
PERCEPTION OF STUDENTS TOWARDS COMPUTER BASED TEST IN AGRICULTURAL SCIENCE TRAININGS AT LADOKE AKINTOLA UNIVERSITY OF TECHNOLOGY (LAUTECH), OGBOMOSO, NIGERIA
}

\author{
Akintonde J.O. * ${ }^{\text {, }}$ Akinola J.O. ${ }^{2}$, Alabi A.A. ${ }^{3}$, Tiamiyu A.O. ${ }^{1}$, Gbadamosi S.A. ${ }^{\text {, }}$ \\ Bamidele B.S. ${ }^{5}$, Alabi A.A. 6
}

${ }^{1}$ Department of Agricultural Extension and Rural Development, P.M.B. 4000, Ladoke Akintola

University of Technology, Ogbomoso, Oyo State of Nigeria.

${ }^{2}$ Olusegun Oke Library, P.M.B. 4000, Ladoke Akintola University of Technology, Ogbomoso,

Oyo State of Nigeria.

${ }^{3}$ Department of Agricultural Economics and Extension, P.M.B. 4494, Osun State Univertsity, Osogbo, Nigeria.

${ }^{4}$ Department of Agricultural Education, Osun State College of Education, P.M.B. 207, IlaOrangun, Nigeria.

${ }^{5}$ Department of Agricultural Extension and Management, Federal College of Agriculture, P.M.B. 5029, Moore Plantation, Ibadan, Oyo State

\begin{abstract}
The study examined the perception of agricultural students towards computer based testing (CBT) in Ladoke Akintola University of Technology, Ogbomoso, Oyo State, Nigeria. Multistage sampling technique was used to select 108 agricultural students of 200level across all the departments in the Faculty of Agricultural Sciences. However, the respondents have different perception toward CBT as mode of assessment newly introduced by the University management. There is significant relationship between some of the selected personal characteristics the respondents (such as department $\{(x 2=68.481)$; age $(x 2=64.389)$; mode of admission (x2=166.056) and basis for supporting CBT examination $(x 2=33.333)$ \} and their perception of CBT mode of examination. The study therefore recommends that CBT mode of examination should be encouraged and this innovation should cut across all other level apart from 100 level students. The academic staff members of different department and faculties should encourage the spread of the innovation across the University at large and the university management and department involved in the CBT examination should come together and provide solution to some of the associated constraints with CBT examination in LAUTECH as this would encourage its full adoption and its usage in the various departments and the entire University at large.

Keywords: Perception; Agricultural Training; Students; Computer Based Test.
\end{abstract}

Keywords: Perception; Agricultural Training; Students; Computer Based Test.

Cite This Article: Akintonde J.O., Akinola J.O., Alabi A.A., Tiamiyu A.O., Gbadamosi S.A., Bamidele B.S., and Alabi A.A.. (2019). "PERCEPTION OF STUDENTS TOWARDS 
COMPUTER BASED TEST IN AGRICULTURAL SCIENCE TRAININGS AT LADOKE AKINTOLA UNIVERSITY OF TECHNOLOGY (LAUTECH), OGBOMOSO, NIGERIA." International Journal of Research - Granthaalayah, 7(3), 48-55. https://doi.org/10.29121/granthaalayah.v7.i3.2019.942.

\section{Introduction}

It is generally recognized that examinations determine the extent to which educational objectives have been achieved as well as the extent to which educational institutions have served the needs of community and society (Shah, 2002). Examinations are not limited to measure educational or societal objectives and needs but incorporate in a way of coping with the educational system (Havens, 2002). Rehmani (2003) briefly described that 'examinations play a significant role in determining what goes on in the classroom in terms of what, and how teachers teach and students learn and can have impact on both teaching and learning'. Wikipedia used test or examinations as alternative terms of assessment and defined it as: 'test or an examination (or exam) is an assessment indeed to measure a test-takers knowledge, skill, aptitude, physical, fitness or classification in many other topics'.

Computer Based Test (CBT) is now an innovation adopted and use for assessment of students in most of Nigeria institution. CBT was first practiced in Ladoke Akintola University of Technology (LAUTECH), Oyo State, Nigeria during 2011/2012 academic session among 100 level students. Computer-based testing is the use of computers to administer tests. Computer Based Test means the candidate sits in front of a computer, the questions are presented on the computer monitor and the candidate submits the answers through the use of keyboard or mouse. CBT have advantages over Paper-based test, both for lecturers that give the test and for the students who participate in the test. CBT allows for more accurate, secure, rapid and more controlled test administration. Administration of test on the computer helps to minimize almost entirely the use of paper printing (Ogunlade and Olafare, 2011).

Computer-based testing (CBT) has become widespread in recent years. Some states now use an online platform as the primary delivery mode for one or more computer-based tests used for accountability purposes. When CBT was emerging in state testing in the early 2000s, Thompson, Thurlow, Quenemoen, and Lehr (2002) examined the implications of CBT for students with disabilities. There was not much literature about the use of CBT for large-scale assessments at that time, and Thompson et al. worked with states to explore what needed to be considered during development for students with disabilities and how states might address the needs of these students for accommodations in a CBT environment. Since the early 2000s, much has occurred in CBT. CBT seems to have advantages over paper and pencil testing, both for states that run the assessment programs and for the students who participate in them. These advantages are recognized by the U.S. Department of Education, which in one of its major initiatives (Race to the Top Assessment Program), encouraged the development of CBT.

There currently is strong interest in CBT and advocates have identified many positive merits of this approach to assessment including: efficient administration, student preference, self-selection options for students, improved writing performance, built-in accommodations, immediate results, efficient item development, increased authenticity, and the potential to shift focus from assessment 
to instruction (e.g., Becker, 2006; Salend, 2009; Thompson et al., 2002). CBT also allows new ways of assessing students that move beyond the traditional multiple choice and constructed response items. For example, innovative assessments are now being developed that enable students to manipulate data and role play. Yet, as states move forward with CBT they are discovering that it is important to consider not only the positive benefits, but also potential negative unintended consequences. These include, for example, the possibility that additional training will be needed for students with disabilities to interact successfully with computers and the challenges of determining the best way to present some accommodations such as screen readers (Thurlow et al., 2010). The successes of transition from one test method to another depend on the extent and ability of testing professionals to communicate the benefits and limitations of that test method to stakeholders (Jones, 2000). The use of computers for assessment can provide several benefits for educators and test-takers, as Oladipo (2009) concludes that Computer-Based Test (CBT) is a system which spurs development in education as well as other sectors of the economy. CBT usually assists to ensure that candidate's identity in the examination hall is efficiently crosschecked. Computer-based test (CBT) is an efficient way for test sponsors to provide a secure, consistent environment for certification and licensure as it also enhances students' experience (Abubakar and Adebayo, 2014).

The study therefore determined the perception of agricultural students towards the CBT examination in LAUTECH, Oyo State, Nigeria. Specifically, it described the personal characteristics of students; examined respondents' basis for supporting CBT and identified constraints associated with CBT examination in LAUTECH.

\section{Methodology}

The study was carried out in LAUTECH and focused mainly on the departments in the Faculty of Agricultural Sciences and only the 200level students of the various departments were involved. The reason was that they were the students in the Faculty that have the CBT examination experience. Multistage sampling technique was adopted in for the study. First stage involved purposive selection of six departments which include Agricultural economics (AEC), Agricultural extension and rural development (AER), Animal production and health (APH), Animal production and Biotechnology (ANB), Crop production and soil science (CPS) and Crop and environmental protection (CEP); thereafter $8 \%$ of the student population of this level (200level) in each department were sampled and this sum up to a total of 108 students that constituted sample size of the study. Descriptive statistical tools used in the study include frequency distribution, percentage, mean and ranking; while Chi-square analysis was used as inferential tool to make inference between the variables.

\section{Results and Discussion}

\subsection{Personal Characteristics of the Respondents}

Result in Table 1 shows that $11.1 \%$ of the respondents sampled were from AEC department, 15.7\%, 21.3\% and 17.6\% were from AERD, CEP and ANB department respectively. Again, 18.5\% and $15.7 \%$ were from APH and CPS department. This implies that all the students of the faculty that pass through CBT examination were actually considered for this study. The variation in the 
percentages may be due to differences in the population of each department sampled. Also majority (55.6\%) of the students sampled were female, while only $44.4 \%$ were male. The differences in the sex of the respondents sampled may be emanated from either admission process or courses transfer; and most (95.3\%) of them were between the age range of less and equal to 30 years. Again majority $(63.9 \%)$ of the students involved in the study gained admission to the University through Pre-degree, while $35.2 \%$ entered through JAMB. It implies that Pre-degree programme is an alternative way where most students gain admission into University programme.

\subsection{Perception of Respondents Towards CBT Assessment}

Table 2 revealed the perception of students toward CBT-examination was determined with 5 Likert scale of measurement and ranked accordingly while the statement that CBT examination gives room for computer literacy had the highest weighted mean score (WMS) of 4.57 and was ranked $1^{\text {st }}$, followed by CBT examination discourage malpractice/I am confident that my grades for online assessment are secured each with wms of $4.20\left(2^{\text {nd }}\right)$, while the statement that online assessment favour some students more than other was ranked least $\left(12^{\text {th }}\right)(\mathrm{wms}=3.63)$. This implies that students have different perception toward CBT examination. The ranking order is expected to be accounted for by differences in their perception from the level of agreement with various perceptional statements about the computer based examination.

\subsection{Basis for supporting CBT}

Table 3 revealed students basis for supporting CBT examination, the responses were multiple and majority $(90.7 \%$ ) indicated that it gives room for computer literacy; while $89.8 \%$ and $88.9 \%$ indicated that CBT examination encourage independent work and it avoids biasness on the part of the examiners. Again $88.0 \%$ each of the students indicated that CBT discourages examination malpractices and ensures timely release of result. This implies that all students admitted that CBT examinations are associated with certain merit which accounted for their basis in supporting CBT examinations.

\subsection{Continuity/Merit over demerit of CBT assessment}

Table 4 revealed that almost all $(91.7 \%)$ of the students support the continuity of CBT examination in LAUTECH, and majority (77.8\%) admitted that benefit of CBT examination outweigh it demerit. This suggests that majority of the population of students sampled are in support the continuity of CBT assessment in LAUTECH.

\subsection{Constraints of CBT assessment and its severity}

Table 5 revealed different identified constraints associated with CBT assessment in LAUTECH and server fluctuation problem had the highest wms of 1.19 and was ranked $1^{\text {st }}$, followed by stress encountered during the arrangement of students in the various CBT centres $\left(2^{\text {nd }}\right)(\mathrm{wms}=1.07)$ and automatic log-out before submission $\left(3^{\text {rd }}\right)(0.83)$, while power failure was ranked least $\left(5^{\text {th }}\right)$ (wms $=0.19)$. This implies that certain constraints are associated with CBT assessment in LAUTECH. 


\subsection{Test of hypothesis}

Table 6 shows the result of Chi-square analysis and some of the independent variables exhibited a significant relationship with dependent variable. The significant variables include department $\left(x^{2}=68.481\right)$, age $\left(x^{2}=64.389\right)$, mode of admission $\left(x^{2}=166.056\right)$ and basis for supporting CBT $\left(x^{2}=33.333\right)$ respectively. It implies that all these afore-mentioned personal characteristics (department, age, mode of admission and basis for supporting CBT examination) of the respondents have decisive influences on their perception of CBT examination in LAUTECH. Therefore, the null hypothesis is rejected, hence alternative hypothesis is accepted.

\section{Conclusion and Recommendations}

Despite the fact that CBT examination is a new innovation in LAUTECH, most of the students in the Faculty of Agricultural Sciences really support it based on its advantages hen compared with the paper and pen examinations. Certain constraints inhibit the CBT examinations as identified by the students which may be based on their perception and experience during CBT examinations. The following recommendation were drawn that CBT mode of examination appeared as a new innovation in LAUTECH, it should be encourage and cut across all other levels; the university management and department involved in CBT examinations should liaise together and provide solutions to various identified constraints associated with CBT examinations in LAUTECH as this would encourage its full adoption and its usage in the various departments and the entire University at large.

Table 1: Distribution of respondents by personal characteristics

\begin{tabular}{|lcc|}
\hline Department & Frequency & Percentage \\
\hline AEC & 12 & 11.1 \\
AERD & 17 & 15.7 \\
CEP & 23 & 21.3 \\
ANB & 19 & 17.6 \\
APH & 20 & 18.5 \\
CPS & 17 & 15.7 \\
\hline Sex & & \\
Male & 48 & 44.4 \\
Female & 60 & 55.6 \\
Age & & \\
$\leq 20$ & 78 & 72.2 \\
21-30 & 25 & 23.1 \\
Above 30 & 5 & 4.6 \\
Mode of admission & & \\
Jamb & 38 & 35.2 \\
Pre-degree & 69 & 63.9 \\
\hline Total & $\mathbf{1 0 8}$ & $\mathbf{1 0 0 . 0}$ \\
\hline
\end{tabular}

Source: Survey, 2014 
Table 2: Distribution of respondents by perception of towards computer based testing

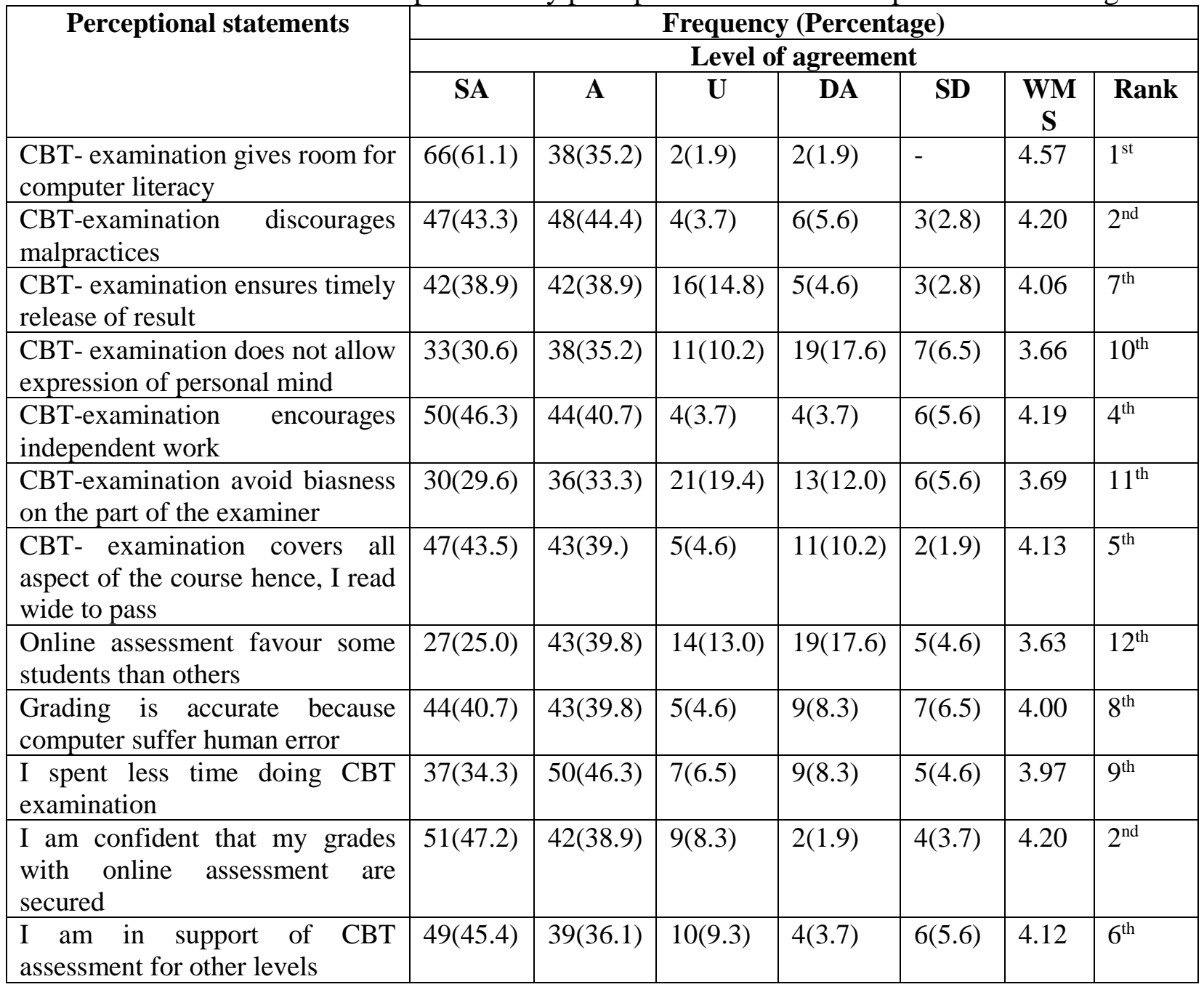

Source: Survey, 2014

Table 3: Distribution of respondents by basis for supporting CBT

\begin{tabular}{|lcc|}
\hline Basis & *Frequency & Percentage \\
\hline It gives room for computer literacy & 98 & 90.7 \\
It discourages examination malpractices & 95 & 88.0 \\
It ensures timely release of results & 95 & 88.0 \\
It encourages independent work & 97 & 89.8 \\
It avoids biasness on the side of the examiners & 96 & 88.9 \\
\hline
\end{tabular}

Source: Survey, 2014

Table 4: Distribution of respondents by continuity and benefit of CBT over demerit

\begin{tabular}{|lcc|}
\hline Continuity & Frequency & Percentage \\
\hline Yes & 99 & 91.7 \\
No & 8 & 7.4 \\
\hline Benefit & & \\
Yes & 84 & 77.8 \\
\hline
\end{tabular}




\begin{tabular}{|lcr|}
\hline No & 24 & 22.2 \\
\hline Total & $\mathbf{1 0 8}$ & $\mathbf{1 0 0 . 0}$ \\
\hline
\end{tabular}

Source: Survey, 2014

Table 5: Distribution of respondents by constraints and level of its severity associated with CBT

\begin{tabular}{|l|c|c|c|c|c|}
\hline \multirow{2}{*}{ Constraints } & \multicolumn{5}{|c|}{ Frequency (Percentage) } \\
\cline { 2 - 6 } & \multicolumn{5}{|c|}{ Level of severity } \\
\hline Arrangement of the venue tend to be stressful & $38(35.2)$ & $40(37.0)$ & $30(27.8)$ & 1.07 & $2^{\text {nd }}$ \\
\hline Server fluctuation while the exam is still on & $43(39.8)$ & $42(38.9)$ & $23(21.3)$ & 1.19 & $1^{\text {st }}$ \\
\hline Power failure & $16(14.8)$ & $16(14.8)$ & $90(83.3)$ & 0.19 & $5^{\text {th }}$ \\
\hline Log-in problem & $20(18.5)$ & $38(35.2)$ & $50(46.3)$ & 0.72 & $4^{\text {th }}$ \\
\hline Automatic log-out associated with password/code & $25(23.1)$ & $40(37.0)$ & $43(39.8)$ & 0.83 & $3^{\text {rd }}$ \\
\hline
\end{tabular}

Source: Survey, 2014

Table 6: Test of significant relationship between the selected socio-economic characteristics of respondents and their perception towards CBT examination

\begin{tabular}{|l|l|l|l|l|l|}
\hline Socio-economic variables & $\mathbf{X}^{2}$-Cal & $\mathbf{D f}$ & $\mathbf{X}^{2}$-Tab & Result & Remark \\
\hline Department & 68.481 & 1 & 3.84 & S & Reject Ho \\
\hline Sex & 1.333 & 1 & 3.84 & NS & Accept Ho \\
\hline Age & 64.389 & 2 & 5.99 & S & Reject Ho \\
\hline Mode of admission & 166.056 & 2 & 5.99 & S & Reject Ho \\
\hline Basis for supporting CBT & 33.333 & 1 & 3.84 & S & Reject Ho \\
\hline Continuity & 3.778 & 5 & 11.07 & NS & Accept Ho \\
\hline
\end{tabular}

Source: Data analysis, 2014

\section{Significant at 0.05 level (2-tailed) \\ NS: Not Significant \\ S: Significant \\ Df: Degree of freedom \\ $\mathrm{X}^{2}$-cal: Chi-square calculated \\ $X^{2}$-tab: Chi-square tabulated}

\section{References}

[1] Abubakar, A. S. \& Adebayo, F. O.(2014). Using Computer Based Test Method for the Conduct of Examination in Nigeria: Prospects, Challenges and Strategies. Mediterranean Journal of Social Sciences, 5 (2) 47-56.

[2] Becker, J. D. (2006). Digital equity in education: A multilevel examination of differences in and relationships between computer access, computer use and state-level technology policies. Education Policy Analysis Archives, 15(3), 1-38.

[3] Havens, A. (2002). Examinations and Learning: An Activity - Theoretical Analysis of the Relationship between Assessment and Learning. Retrieved December 03, 2010 from http://www.leeds.ac.uk/educol/documents/00002238.htm

[4] Jones, J. P. (2000). Promoting stakeholder acceptance of CBT. Paper presented at the computer based testing applications for the new millennium by the Association of Test Publishers, New York.

[5] Rehmani, A. (2003). Impact of Public Examination System on Teaching and Learning in Pakistan. Retrieved December 24, 2010 from http://www.aku.edu/AKUEB/pdfs/pubexam.pdf 
[6] Salend, S. J. (2009). Technology-based classroom assessments: Alternatives to testing. Teaching Exceptional Children, 41(6), 48-58.

[7] Shah, J. H. (2002). Validity and Credibility of Public Examinations in Pakistan. An Unpublished Thesis Submitted for the Degree of Ph. D., in the Department of Education, Islamia University Bahawalpur, Pakistan.

[8] Thurlow, M.; Lazarus, S. S.; Albus, D. \& Hodgson, J. (2010). Computer-based Testing: Cites and Considerations, Synthesis Report 78.

[9] Thompson, S. J.; Thurlow, M. L.; Quenemoen, R. F. \& Lehr, C. A. (2002). Access to computerbased testing for students with disabilities (Synthesis Report 45). Minneapolis, MN: University of Minnesota, National Center on Educational Outcomes.

[10] Ogunlade, O.O. and Olafare, F.O. (2011). Students' characteristics as predictors of their perception on the effectiveness of CBT in Nigeria. Pakistan Journal of education, Vol. XXVIII, pg. 17.

[11] Oladipo, T. (2009). More tertiary institutions embrace electronic testing. Retrieved from EtcIntranet Portal Copyright 28 March.

*Corresponding author.

E-mail address: joakintonde@ lautech.edu.ng 